\title{
AVALIAÇÃO DA EFICIÊNCIA HIDROLÓGICA DE PAVIMENTOS PERMEÁVEIS E SISTEMAS DE BIORRETENÇÃO EM LOTEAMENTO RESIDENCIAL
}

\section{Evaluation of hydrological efficiency of permeable pavements and bioretention systems in a built-up residential area}

\author{
Lucas Humberto Silva ${ }^{1}$, Frederico Carlos Martins de Menezes Filho ${ }^{2}$
}

Recebido em 22 de fevereiro de 2019; aceito em 03 de agosto de 2019; disponível on-line em 17 de setembro de 2019.

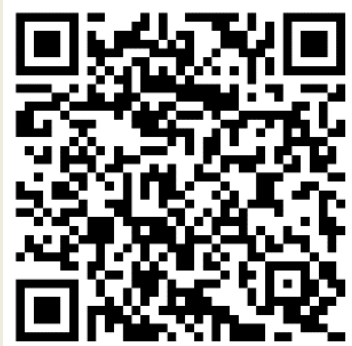

PALAVRAS CHAVE:

Drenagem urbana;

Método Santa Bárbara;

Técnicas compensatórias;

Eficiência hidrológica;

Patrocínio, MG.

\section{KEYWORDS:}

Urban Drainage;

Santa Bárbara method;

Best management

practices;

Hydrological efficiency;

Patrocínio, MG.

* Contato com os autores:

${ }^{1}$ e-mail: lucassilvah15@gmail.com (L. H. Silva)

Graduando em Engenharia Civil, Universidade Federal de Viçosa - Campus Rio Paranaíba.

2e-mail: menezesfilho.frederico@gmail.com (F. C. M. Menezes Filho)

Engenheiro Civil, Doutor em Recursos Hídricos e Saneamento Ambiental (IPH-UFRGS), Prof. Adjunto, Universidade Federal de Viçosa Campus Rio Paranaíba.
RESUMO: Visto os avanços no âmbito da drenagem urbana ao longo dos anos, o desafio para projetar sistemas de drenagem eficientes ainda é complexo devido à grande impermeabilização dos espaços urbanos, e aos efeitos advindos das mudanças do ciclo hidrológico nas condições urbanas. O presente trabalho analisou a eficiência hidrológica de sistemas de biorretenção e pavimentos permeáveis em um loteamento residencial em Patrocínio-MG. A eficiência foi calculada por meio da comparação dos volumes escoados provenientes de diversas simulações hidrológicas utilizando o Método Santa Bárbara. Os resultados da eficiência para os sistemas de biorretenção variaram de $7 \%$ a $12,9 \%$, enquanto que para o uso combinado dos sistemas de biorretenção com pavimentos permeáveis, os resultados alcançaram a faixa de $30,01 \%$ a $49,84 \%$. Evidencia-se, portanto, a aplicabilidade das técnicas compensatórias em conjunto, promovendo a redução do escoamento superficial durante eventos chuvosos severos, além da melhoria paisagística e sustentável da área de estudo.

ABSTRACT: Despite the evolution in the field of urban drainage over the years, the challenge of design effective drainage systems is still complex due to the intense waterproof surfaces and the effects of water cycle change in urban areas. This paper analyzed the hydrological efficiency of bioretention systems and permeable pavements in a residential subdivision in Patrocínio-MG. Efficiency was calculated by comparing the surface runoff volumes from several hydrological simulations using the Santa Barbara Method. Efficiency results for bioretention systems ranged from $7 \%$ to $12,9 \%$, while for the combined use of bioretention systems with permeable pavements, the obtained results were $30,01 \%$ to $49,84 \%$. Therefore, stands out the importance of combined use of best management practices, making possible the surface runoff reduction during severe rainfall events, as well as the landscape and sustainable improvement of the study area. 


\section{INTRODUÇÃO}

Apesar da evolução no campo da drenagem urbana ao longo dos anos, o desafio para dimensionar sistemas de drenagem eficazes ainda é complexo. Somado aos efeitos advindos das mudanças no comportamento do ciclo hidrológico nos centros urbanos e da intensa impermeabilização das superfícies durante o processo de urbanização, a magnitude e frequência de problemas como cheias urbanas e alagamentos, tende a aumentar, e consequentemente, a probabilidade de prejuízos materiais e perdas humanas, tende a seguir na mesma proporção (ZHOU, 2014; MELO et al., 2015).

Devido à evolução do problema, soluções sustentáveis conhecidas como Green Infrastructure, ou em português, infraestrutura verde (CNT, 2010; USEPA, 1999), passaram a ser mais utilizadas em países desenvolvidos, visando diminuir os impactos gerados pela drenagem convencional, bem como a auxiliar os sistemas atuais frente a eventos chuvosos cada vez mais severos (ECKART, MCPHEE e BOLISETTI, 2017). No Brasil, tais práticas são conhecidas também como técnicas compensatórias ao manejo das águas pluviais (BAPTISTA et al. 2005).

Dentre as técnicas compensatórias disponíveis, citam-se os telhados verdes, os pavimentos permeáveis, os sistemas de biorretenção e as bacias e reservatórios detenção e retenção (CRUZ, SOUZA e TUCCl, 2007; AGOSTINHO e POLETO, 2012; ALAMY FILHO et al., 2016). Destes, os sistemas de biorretenção se destacam como os mais utilizados nos países que utilizam tais práticas em conjunto com os sistemas de drenagem convencionais (DAVIS et al., 2009; ROY-POIRIER, CHAMPAGNE e FILION, 2010, WARDYNSKI e HUNT, 2012), uma vez que são facilmente instaladas e oferecerem um resultado satisfatório no controle de vazões de pico e qualidade da água de escoamento.

Entretanto, no Brasil o tema ainda aparece com literatura reduzida (MIGUEZ, VERÓL e REZENDE, 2016; TUCCI, 2007) e com poucos exemplos de aplicações práticas (CADORE, 2016; DANIEL JUNIOR, 2013; MELO et al., 2014; MELO et al., 2015). Assim, ressalta-se a importância do referido estudo na avaliação da eficiência destas estruturas na redução do escoamento superficial, quando avaliadas individualmente ou em associação com outras estruturas compensatórias, como os pavimentos permeáveis.

\section{OBJETIVO}

Diante do exposto, este trabalho objetiva avaliar a eficiência hidrológica de sistemas de biorretenção e pavimentos permeáveis em loteamento urbano, situado no município de Patrocínio-MG, através da simulação de cenários contemplando diversos usos e ocupação do solo, bem como, distintos eventos pluviométricos.

\section{DRENAGEM URBANA}

A Lei 11.445 (BRASIL, 2007), conhecida como a Lei do Saneamento, trata no artigo 20, inciso I, alínea $d$, que a drenagem urbana é constituída:

Pelas atividades, pela infraestrutura

e pelas instalações operacionais de drenagem de águas pluviais, de transporte, detenção ou retenção para o amortecimento de vazões de cheias, tratamento e disposição final das águas pluviais drenadas, contempladas a limpeza e a fiscalização preventiva das redes.

Dada a definição pela Lei 11.445, Souza (2013) destaca que os sistemas de drenagem no Brasil sempre se basearam na busca de um sistema hidraulicamente eficiente, seguindo uma concepção higienista, ou seja, no sentido de tornar o ambiente salubre, criando estruturas de micro e macrodrenagem com o objetivo de conduzir o escoamento para fora das cidades o mais rápido possível.

Entretanto, a falta de um plano diretor eficaz, com boa compreensão do que significa a hidrologia urbana no desenvolvimento de uma cidade, faz com que muitas áreas urbanas sofram 
com alagamentos, mesmo sob chuvas curtas (COSTA, SIQUEIRA e MENEZES FILHO; 2007).

Tanto Philippi Júnior (2005), quanto Tucci e Meller (2007) corroboram esta visão, afirmando que a falta de planejamento e de uma gestão sustentável integrada aos sistemas de drenagem convencionais, acompanhados de um histórico de baixos investimentos na área, são motivos para que ocorram vários casos de sobrecarga destes sistemas.

Já no município de Patrocínio, situado na região do Alto Paranaíba, Minas Gerais, cuja população é de aproximadamente 90.041 habitantes (IBGE, 2018), realizou-se uma avaliação quanto ao saneamento básico municipal, resultando na elaboração do Plano Municipal de Saneamento Básico - PMSB (PATROCÍNIO, 2016) que traça um diagnóstico do saneamento na cidade e propõe soluções para os problemas identificados. Dentre os problemas constatados quanto ao manejo de águas pluviais, destacam-se: a inexistência de cadastro e detalhamento da rede de microdrenagem; estudo hidrológico atualizado das bacias; Plano Diretor de Drenagem e a grande ocupação nas áreas de inundação dos cursos d'água urbanos.

Neste contexto, um fator que contribui para a situação crítica do sistema de drenagem atual, é a última versão da lei de uso e ocupação do solo - Lei Complementar №132/2014 (PATROCÍNIO, 2014) que determina que apenas 10 \% da área do lote em zonas residenciais não sejam impermeabilizadas. Este valor é inferior se comparado com os valores mínimos determinados por municípios próximos como Uberlândia, que através da Lei Complementar № 525/2011 (UBERLÂNDIA, 2011) e Patos de Minas, através da Lei Complementar № 320/2008 (PATOS DE MINAS, 2008); determinam no mínimo 20 \% sobre a área total.

\subsection{SISTEMAS DE BIORRETENÇÃO}

Os sistemas de biorretenção são estruturas promissoras que fazem parte das técnicas compensatórias e que buscam a restauração do ciclo hidrológico natural através da retenção, infiltração e evapotranspiração (Prince George's County (PGC), 2007 e MOURA, 2013).

Como práticas de biorretenção e infiltração citam-se os jardins de chuva, as biovaletas, as lagoas pluviais e os canteiros pluviais (CIRIA, 2015; CNT, 2010; CORMIER e PELLEGRINO, 2008; MOURA, 2013), dos quais os jardins de chuva representam a forma mais usual de técnica compensatória nos Estados Unidos (DAVIS et al., 2009).

Sua ampla utilização se dá devido à facilidade com que ele é integrado ao meio urbano e ao paisagismo (WARDYNSKI e HUNT, 2012), oferecendo um bom desempenho na retenção de poluentes e na redução das vazões de pico, cuja redução pode variar conforme desempenho definido em projeto, sendo relatadas experiências onde a redução da vazão de pico varia de 31 a 99 $\%$ do escoamento que entra na célula do jardim (CITY OF CHICAGO, 2003; HUNT et al., 2006; UNHSC, 2005; HUNT et al., 2008; ROY-POIRIER et al., 2010; BROWN E HUNT, 2011; DEBUSK e WYNN, 2011).

Apesar dos benefícios apresentados, os sistemas de biorretenção apresentam limitações, como a necessidade de manutenção periódica, além de ter reduzida capacidade de redução do escoamento sob eventos extremos. Outros pontos que prejudicam o bom funcionamento dos sistemas de biorretenção são: lençol freático raso, leito de rochas superficial, solos potencialmente colapsíveis e terrenos muito inclinados (MOURA, 2013; PAUS e BRASKERUD, 2014; ECKART, MCPHEE e BOLISETTI, 2017).

\subsection{PAVIMENTOS PERMEÁVEIS}

Os pavimentos permeáveis promovem a diminuição do escoamento através da infiltração, podendo alcançar situações semelhantes às condições naturais de infiltração, ou até mesmo a taxas superiores se comparadas com os valores antes da utilização do solo (ARAÚJO, TUCCI e GOLDENFUM, 2000).

Dentre os tipos utilizados atualmente, 
destacam-se os pavimentos com blocos intertravados, concreto poroso, asfalto poroso, pavimento de blocos vazados com agregados ou com grama (ABCP, 2013).

$\mathrm{Em}$ áreas urbanas densamente ocupadas, as superfícies destinadas ao sistema viário e aos estacionamentos ocupam um espaço significativo, podendo chegar a $30 \%$ da área da bacia de drenagem.

Devido à grande área de aplicação, Maus, Righes e Buriol (2007) aferiram que sua eficiência com relação ao percentual do escoamento superficial retido chega a $100 \%$ para uma precipitação acumulada de 236,62 mm. Araújo et al. (1999) também verificou elevados índices de eficiência, através da simulação de um evento de 18,33 mm, com intensidade pluviométrica de $111,9 \mathrm{~mm} / \mathrm{h}$, avaliando que o escoamento superficial foi de apenas $2,73 \%$.

Da mesma forma que nos sistemas de biorretenção, os pavimentos permeáveis oferecem inúmeros outros benefícios, além da redução das vazões derivadas de eventos chuvosos, como promover a recarga do lençol freático, melhorar a qualidade de água através da infiltração, diminuição dos ruídos e redução da necessidade de tratamento de água (CNT, 2010 e PINTO, 2011).

Por outro lado, de acordo com Miguez, Veról e Rezende (2016) para aplicação deste tipo de técnica compensatória, deve ser observado o tipo de tráfego no local, uma vez que sua resistência é inferior ao pavimento convencional. Terrenos muito íngremes também contribuem para reduzir a eficiência dos pavimentos permeáveis, uma vez que a capacidade de infiltração nestas condições é reduzida.

\section{METODOLOGIA}

\section{1 ÁREA DE ESTUDO}

A área de estudo, apresentada na Figura 1, compreende um loteamento residencial, situado no município de Patrocínio-MG, cuja área total é de $364.270,37 \mathrm{~m}^{2}$. Considerou-se para o estudo, a área interna à linha limítrofe vermelha, definida como divisor de águas e suposto muramento para utilização da metodologia apresentada neste trabalho.

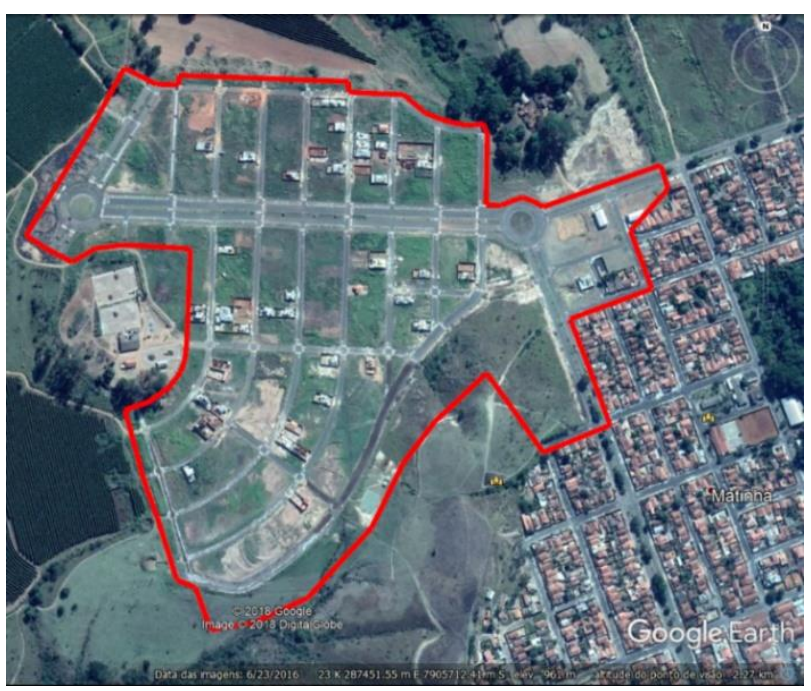

FIGURA 1: Loteamento do bairro Belvedere em Patrocínio/MG.

FONTE: Adaptado de Google Earth.

A partir da área total, verificou-se que 183.672,13 $\mathrm{m}^{2}$ correspondem à área a ser edificada, 37.379,10 $\mathrm{m}^{2}$ referem-se à área verde remanescente, $13.735,77 \mathrm{~m}^{2}$ de área institucional, pertencente ao município, $6.699,81 \mathrm{~m}^{2}$ de área verde/recreação e 122.783,56 $\mathrm{m}^{2}$ de área pavimentada.

\subsection{CENÁRIOS DE ANÁLISE DO SISTEMA DE DRENAGEM}

A eficiência hidrológica dos sistemas de biorretenção e dos pavimentos permeáveis foi obtida comparando-se cinco cenários com distintos valores de áreas impermeáveis, representativos do adensamento populacional e da taxa de permeabilidade assumidas. Também nesta análise definiram-se diversos eventos chuvosos pela consideração da variação das durações e tempos de retorno.

Os dois primeiros cenários, referem-se estritamente à situação atual e futura de adensamento populacional, sem a inserção das técnicas compensatórias. Nos demais cenários, tem-se a consideração das técnicas compensatórias aos dois cenários iniciais para efeitos de comparação. 
Assim, tem-se:

- Cenário 1: situação atual do loteamento, baseado na imagem obtida de 2016, conforme apresentado na Figura 2;

- Cenário 2: situação hipotética futura, considerando todo o loteamento ocupado, considerando a taxa mínima de permeabilidade, igual a $10 \%$, definida pela Lei complementar № 132/2014 do município de Patrocínio;

- Cenário 3: situação hipotética considerando a inserção de sistemas de biorretenção na situação descrita pelo cenário 2 (Cenário $2+$ sistemas de biorretenção);

- Cenário 4: situação hipotética, considerando a inserção de sistemas de biorretenção, conforme cenário 3 , além da assunção da taxa de permeabilidade de $20 \%$, valor mínimo definido por município próximos como Uberlândia e Patos de Minas, conforme descrito no item 3.1;

- Cenário 5: situação hipotética conforme cenário 4, considerando a substituição da pavimentação convencional existente por pavimentos permeáveis, associando então duas técnicas compensatórias (sistemas de biorretenção e pavimentos permeáveis).

É importante destacar que o cenário 1 não foi utilizado como base para o cálculo da eficiência hidrológica, sendo utilizado apenas para apresentar a situação hidrológica atual do loteamento, que se encontra pouco urbanizado. Tal situação não reflete o cenário mais crítico para a drenagem da área de estudo.

A área dos pavimentos permeáveis correspondeu à área pavimentada atual, conforme descrita pelo item 4.1, menos a área dos sistemas de biorretenção, uma vez que os jardins de chuva foram acomodados em áreas que atualmente são impermeáveis, correspondendo às faixas de serviço das calçadas de cada lote da área de estudo. A largura mínima adotada para os jardins de chuva, conforme NBR 9050 (ABNT, 2015), Acessibilidade a edificações, mobiliário, espaços e equipamentos urbanos, foi de $70 \mathrm{~cm}$. O comprimento adotado para os jardins de chuva foi igual a 6 metros, uma vez que a testada mínima definida pela Lei complementar № 131/2014 Parcelamento do solo (PATROCíNIO, 2014) é de 10 metros.

Dessa forma, para cada lote foram definidos 4 metros para entrada e saída de veículos. Assim, cada unidade residencial abrangeu 4,2 $\mathrm{m}^{2}$ de sistemas de biorretenção em seus calçamentos. Considerou-se também que todos os lotes possuem o mesmo sistema de biorretenção, independente de variações na testada dos lotes.

As áreas de canteiros centrais de avenidas e rotatórias foram consideradas como áreas destinadas à instalação de sistemas de biorretenção.

\subsection{CHUVA DE PROJETO}

Os eventos chuvosos foram calculados com base na equação que relaciona a intensidade, duração e frequência (IDF), apresentada pela Equação 1, adotando-se os parâmetros obtidos pelo software Plúvio 2.1 para a cidade de Patrocínio (GPRH, 2018).

$$
i=\frac{K \times T^{a}}{(t+b)^{c}}
$$

Em que: i: intensidade pluviométrica (mm/hora); T: tempo de recorrência (anos); t: duração do evento (minutos); $\mathrm{K}=5517,711$; $\mathrm{a}=$ 0,$191 ; b=34,245 ; c=1,064$ (GPRH, 2018).

\subsection{TEMPO DE RETORNO}

Os tempos de retorno (T) assumidos para o cálculo das precipitações corresponderam a: 0,$5 ; 2 ; 5$ e 10 anos, de forma a analisar a eficiência hidrológica em relação à eventos mais severos, porém menos frequentes; como também à eventos recorrentes, de menor intensidade pluviométrica.

\subsection{TEMPO DE CONCENTRAÇÃO DA ÁREA DE ESTUDO}

O tempo de concentração da área de estudo, foi obtido utilizando-se a Equação 2 
(Germano) e 3 (Schaake) ambas apresentadas por Alamy Filho et al. (2016).

$$
t_{c}=18,628 \frac{L^{0,882}}{\alpha^{0,272}}
$$

Em que: $t_{c}$ : tempo de concentração (minutos); L: comprimento axial do loteamento (ou caminho preferencial do escoamento, a partir da topografia) (Km); $\alpha$ : porcentagem impermeável da área total.

$$
t_{c}=0,67 \frac{L^{0,882}}{\alpha^{0,272} \cdot S^{0,16}}
$$

Em que: $S:$ declividade média do loteamento $(\mathrm{m} / \mathrm{m})$.

Adotou-se o menor tempo de concentração calculado entre as duas equações para utilização como a primeira duração nas simulações hidrológicas, conforme o item 4.6; correspondendo a um evento de maior intensidade pluviométrica.

\subsection{SIMULAÇÕES HIDROLÓGICAS}

As simulações hidrológicas foram realizadas considerando eventos pluviométricos calculados pela Equação 1, assumindo-se a variação tanto para o período de retorno $(T)$, descrito no item 4.4; quanto para as durações, a saber: iguais ao tempo de concentração da área de estudo descrito no item 4.5 e, iguais a 15, 30, 60, 360, 720 e 1440 minutos.

Além da variação da duração dos eventos chuvosos e dos períodos de retornos assumidos, considerou-se a variação temporal dos mesmos através das curvas sintéticas de Huff (1967), apresentadas na Figura 2, obtidas a partir de Methods e Durrans (2003).

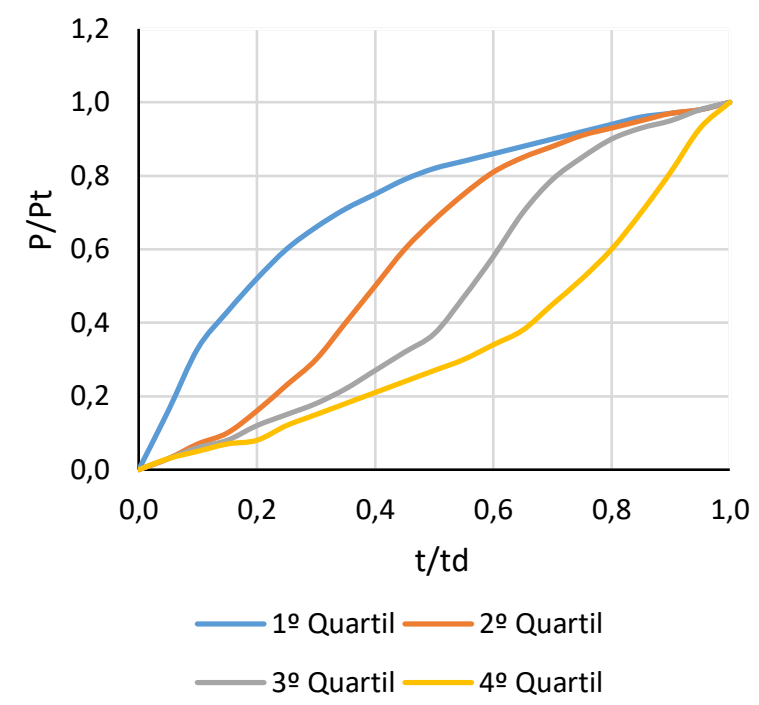

FIGURA 2: Curvas sintéticas de Huff. Legenda: P - precipitação; Pt - precipitação total; t - duração; td - duração total.

FONTE: Autoria própria.

As equações de cada curva apresentada na Figura 3 são detalhadas na Tabela 1.

\begin{tabular}{|c|c|c|}
\hline Equação & Quartil & $\begin{array}{c}\text { Duração (td) } \\
\text { (Horas) }\end{array}$ \\
\hline$\frac{P}{P_{t}}=1,9088 \cdot\left(\frac{t}{t_{d}}\right)^{3}-4,0968 .\left(\frac{t}{t_{d}}\right)^{2}+3,1842 .\left(\frac{t}{t_{d}}\right)+0,0218$ & 10 & $\mathrm{td}<6$ \\
\hline$\frac{P}{P_{t}}=4,2875 \cdot\left(\frac{t}{t_{d}}\right)^{4}-10,599 \cdot\left(\frac{t}{t_{d}}\right)^{3}+7,7619 \cdot\left(\frac{t}{t_{d}}\right)^{2}-0,4765 \cdot\left(\frac{t}{t_{d}}\right)+0,0225$ & 20 & $6<\mathrm{td}<12$ \\
\hline $\begin{array}{c}\frac{P}{P_{t}}=42,434 .\left(\frac{t}{t_{d}}\right)^{6}-118,88 .\left(\frac{t}{t_{d}}\right)^{5}+117,92 .\left(\frac{t}{t_{d}}\right)^{4}-49,505 .\left(\frac{t}{t_{d}}\right)^{3}+9,0268 \\
\left(\frac{t}{t_{d}}\right)^{2}-0,0039 .\left(\frac{t}{t_{d}}\right)+0,0041\end{array}$ & 3으 & $12<\mathrm{td}<24$ \\
\hline $\begin{array}{c}\frac{P}{P_{t}}=-20,591 \cdot\left(\frac{t}{t_{d}}\right)^{6}+55,342 \cdot\left(\frac{t}{t_{d}}\right)^{5}-53,606 \cdot\left(\frac{t}{t_{d}}\right)^{4}+23,45 \cdot\left(\frac{t}{t_{d}}\right)^{3}-4,3118 \cdot\left(\frac{t}{t_{d}}\right)^{2}+0,7184 . \\
\left(\frac{t}{t_{d}}\right)+0,001\end{array}$ & 40 & $\mathrm{td}>24$ \\
\hline
\end{tabular}

TABELA 1 - Equações das curvas de Huff. 
4.7 CARACTERÍSTICAS DO SOLO DA ÁREA DE ESTUDO E DEFINIÇÃO DA CURVA NÚMERO (CN)

O escoamento gerado por cada evento chuvoso é obtido através do método Soil Conservation Service (SCS) que depende do tipo de solo e/ou pavimento da área de estudo, e de sua cobertura vegetal, caracterizado pelo parâmetro adimensional denominado curva número (CN).

Uma vez que o tipo de solo influencia no escoamento superficial, de acordo com Júnior, Malavolta e Cabral (2000) e Nascimento (2010), verifica-se que para o município de Patrocínio-MG, o solo predominante é do tipo Latossolo Vermelho-Amarelo álico de textura média.

Consoante o Instituto Agronômico de São Paulo (IAC) e a Empresa Brasileira de Pesquisa Agropecuária (EMBRAPA), tal solo apesar de ser predominantemente argiloso, tem comportamento de solo arenoso, possuindo alta permeabilidade e baixa retenção de água. Deste modo, estabeleceu-se para o solo da área de estudo, como pertencente ao grupo hidrológico $A$.

Para determinação do $\mathrm{CN}$ do loteamento, definiram-se apenas as condições médias de umidade. Visto a existência de áreas permeáveis e impermeáveis, o valor final de $\mathrm{CN}$ foi obtido por meio de uma média ponderada, expressa por meio da Equação 4.

$$
\begin{gathered}
\mathrm{CN}=\frac{\mathrm{CN}_{\mathrm{b}} \cdot \mathrm{AB}+\mathrm{CN}_{\mathrm{p}} \cdot \mathrm{AP}+\mathrm{CN}_{\mathrm{i}} \cdot \mathrm{Al}+\mathrm{CN}_{\mathrm{pav}} \cdot \mathrm{APP}}{\mathrm{AT}} \quad \mathrm{Eq} \cdot[4] \\
\mathrm{Em} \text { que: } \quad \mathrm{CN}_{\mathrm{b}}: \quad \mathrm{CN} \text { para áreas }
\end{gathered}
$$
correspondentes aos sistemas de biorretenção; $\mathrm{AB}$ : Área dos sistemas de biorretenção $\left(\mathrm{m}^{2}\right) ; \mathrm{CN}_{\mathrm{p}}$ : $\mathrm{CN}$ para áreas permeáveis obrigatórias por lei; $\mathrm{AP}$ : área permeável $\left(\mathrm{m}^{2}\right) ; \quad \mathrm{CN}_{\mathrm{i}}: \mathrm{CN}$ para áreas impermeáveis e/ou edificadas; $\mathrm{Al}$ áreas impermeáveis e/ou edificadas $\left(\mathrm{m}^{2}\right) ; \mathrm{CN}_{\mathrm{pav}}$ : $\mathrm{CN}$ pavimentos permeáveis; APP: Área dos pavimentos permeáveis; AT: área total do loteamento $\left(\mathrm{m}^{2}\right)$.

Consoante Tucci et al. (2004), para os solos do tipo $\mathrm{A}$, os valores de $\mathrm{CN}$ para bacias suburbanas adotadas para cada área do loteamento foram: a) Área dos sistemas de biorretenção: $\mathrm{CN}=39$ - Espaço aberto com mais de $75 \%$ da área com grama, consoante Carpenter (2015); b) Área dos pavimentos permeáveis: $\mathrm{CN}=$ 76 (Vias com paralelepípedos); c) Área permeável obrigatória por lei: $\mathrm{CN}=45$ (Bosques ou zonas com cobertura ruim) e d) Área impermeável: $\mathrm{CN}=98$ (Arruamentos e estradas).

\subsection{MÉTODO SANTA BÁRBARA}

O método de Santa Bárbara (STUBCHAER, 1980) foi utilizado por meio de uma rotina escrita em linguagem Visual Basic for Applications (VBA), desenvolvido por Sousa (2008), para avaliar o efeito de armazenamento das técnicas compensatórias. Para tal, adaptou-se o mesmo para as condições da área de estudo, utilizando os parâmetros da Equação 1 e as equações de Huff, conforme apresentadas na Tabela 1.

O método inicia com o cálculo da chuva efetiva através do método SCS. A parcela da chuva que se infiltra é obtida a partir da diferença entre a precipitação total, calculada pela equação 5 , e o escoamento acumulado, calculada pela Equação 7.

$$
P_{\text {total }}=i . t_{d} \quad \text { Eq. [5] }
$$

Em que: $P_{\text {total }}$ : precipitação total $(\mathrm{mm})$; i intensidade pluviométrica obtida pela equação 1 $(\mathrm{mm} / \mathrm{h}) ; t_{d}$ : tempo de duração do evento $(\mathrm{h})$ conforme item 4.5 .

Como o método considera uma discretização do evento chuvoso, faz-se necessário que a precipitação em cada intervalo de tempo seja obtida através da curva de Huff mais adequada, de acordo com o tipo de evento chuvoso, conforme Equação 6.

$$
\mathrm{P}_{\mathrm{t}}=\mathrm{P}_{\text {total }} . \%_{\text {HUFF }}
$$

Sendo: $\mathrm{P}_{\mathrm{t}}$ : Precipitação por intervalo de tempo ( $\mathrm{mm}$ ), е \%ниғ: porcentagem de chuva que ocorre por intervalo de tempo, segundo a distribuição de Huff.

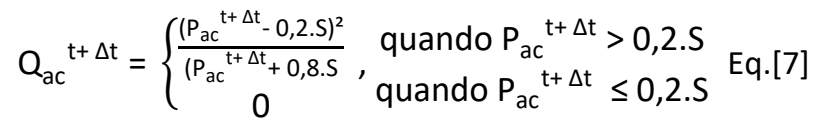


Em que: $Q_{a c}{ }^{t+\Delta t}$ : escoamento acumulado (mm) no intervalo de tempo $\mathrm{t}+\Delta \mathrm{t} ; \mathrm{Pac}^{\mathrm{t}}{ }^{+}+\Delta \mathrm{t}$ : precipitação acumulada $(\mathrm{mm})$ no intervalo de tempo $t+\Delta t$; S: potencial máximo de retenção da área de contribuição $(\mathrm{mm})$, calculado pela Equação 8.

$$
S=\frac{25400}{C N}-254
$$

Em que: CN: Curva número da área de estudo calculado pela Equação 4.

Após isso, calcula-se o escoamento acrescido por intervalo de tempo, devido ao processo iterativo, obtido pela diferença de escoamento no instante $t+\Delta t$ e no instante $t$ através da Equação 9, e em seguida, calcula-se a infiltração para o mesmo intervalo de tempo, através da Equação 10.

$$
\mathrm{Q}_{\mathrm{t}}=\mathrm{Q}_{\mathrm{ac}}{ }^{\mathrm{t}+\Delta \mathrm{t}}-\mathrm{Q}_{\mathrm{ac}}{ }^{\mathrm{t}}
$$

Em que: Qt: Escoamento no intervalo de tempo $\mathrm{t}(\mathrm{mm})$.

$$
\operatorname{Inf}_{\mathrm{t}}=\mathrm{P}_{\mathrm{t}}-\mathrm{Q}_{\mathrm{t}} \quad \text { Eq.[10] }
$$

Em que: Inf : Infiltração no intervalo de tempo $\mathrm{t}(\mathrm{mm})$.

Através das Equações 11 e 12, são calculados os escoamentos ( $\left.i_{\text {perm }}\right)$ e ( $\left.i_{\text {imp }}\right)$ provenientes das áreas permeáveis e impermeáveis respectivamente.

$$
\begin{aligned}
& \mathrm{i}_{\text {imp }}(\mathrm{mm} / \mathrm{h})=\frac{\mathrm{P}_{\mathrm{t}}}{\Delta \mathrm{t}} \\
& \mathrm{i}_{\text {perm }}(\mathrm{mm} / \mathrm{h})=\frac{\mathrm{P}_{\mathrm{t}}}{\Delta \mathrm{t}}
\end{aligned}
$$

Em que: $\Delta t$ : incremento em horas utilizado para cada passo iterativo do método, devido à discretização do evento chuvoso, equivalendo ao número de pontos que resultam no hidrograma final.

Por fim, as Equações 13 e 15, fornecem as vazões de entrada e saída do reservatório imaginário, respectivamente.

$$
\mathrm{Q}\left(\mathrm{m}^{3} / \mathrm{s}\right)=\left[\mathrm{i}_{\mathrm{imp}} \cdot \mathrm{d}-\mathrm{i}_{\text {perm }} \cdot(1-\mathrm{d})\right] \cdot A \text { Eq.[13] }
$$

Em que: A: área total do loteamento em estudo $\left(\mathrm{m}^{2}\right)$; $\mathrm{d}$ : porcentagem de área impermeável no loteamento, calculado através da Equação 14.

$$
\mathrm{d}=\frac{\mathrm{Al}}{\mathrm{AT}} \quad \text { Eq. [14] }
$$

Em que: Al: áreas impermeáveis e/ou edificadas $\left(m^{2}\right)$; AT: área total do loteamento $\left(m^{2}\right)$.

$$
Q\left(m^{3} / s\right)_{t+1}=Q_{t}+k_{r}\left(I_{t}+I_{t+1}-2 . Q_{t}\right) \quad \text { Eq.[15] }
$$

Em que: $k_{r}$ : Coeficiente de retardo, calculado pela Equação 16.

$$
\mathrm{k}_{\mathrm{r}}=\frac{\Delta \mathrm{t}}{2 \cdot \mathrm{t}_{\mathrm{c}}+\Delta \mathrm{t}}
$$

Em que: $t_{c}:$ Tempo de concentração, adotado através das Equações 2 ou 3.

\subsection{EFICIÊNCIA HIDROLÓGICA}

A eficiência hidrológica foi obtida através da porcentagem do escoamento que deixa de escoar ao sistema convencional, devido à ação de retardo por parte dos sistemas de biorretenção, dos pavimentos permeáveis, e da variação das áreas impermeáveis, através da Equação 17, apresentada por Alamy Filho et al. (2016).

$$
E(\%)=\frac{100 \cdot\left(V_{i}-V_{s}\right)}{V i}
$$

Em que: $V_{i}$ : volume de escoamento gerado na situação atual e hipotética futura do loteamento completamente ocupado e adensado (cenário 2); e $\mathrm{V}_{\mathrm{s}}$ : Volume total escoado para as situações dos cenários 3, 4 e 5 .

\section{RESULTADOS}

Foram realizadas 140 simulações a fim de se obter a variação das vazões de pico e escoamento superficial para cada cenário estabelecido. Na Tabela 2, são descritos os parâmetros de cálculo utilizados. Na Figura 3, apresentam-se os resultados de eficiência hidrológica obtidos para cada cenário de análise, a partir das simulações realizadas.

Para o cenário 3 , nota-se que os sistemas de biorretenção são pouco efetivos frente à uma grande área impermeável, considerando que neste arranjo, representam apenas $3,7 \%$ do total da área de estudo. Os resultados de eficiência obtidos variam de $2,53 \%$ a $4,86 \%$, sendo o maior valor, resultante de um evento com duração igual a 15 minutos, e tempo de recorrência de 6 meses. 
TABELA 2 - Parâmetros de cálculo para cada cenário analisado.

\begin{tabular}{cccccccc} 
& & \multicolumn{5}{c}{ Área resultantes $\left(\mathrm{m}^{2}\right)$} & CN \\
Cenário & $\begin{array}{c}\text { Tc } \\
(\mathrm{min})\end{array}$ & $\begin{array}{c}\text { Área } \\
\text { verde }\end{array}$ & $\begin{array}{c}\text { Área } \\
\text { pavimento } \\
\text { Permeável }\end{array}$ & $\begin{array}{c}\text { Área } \\
\text { impermeável }\end{array}$ & $\begin{array}{c}\text { Área } \\
\text { biorretenção }\end{array}$ & $\begin{array}{c}\text { Área } \\
\text { permeável } \\
\text { total (\%) }\end{array}$ & Condição II \\
\hline 1 & 1,47 & $219.015,5$ & 0,0 & $145.254,8$ & 0 & 60,12 & 66,13 \\
\hline 2 & 1,21 & $63.819,6$ & 0,0 & $300.450,7$ & 0 & 17,52 & 88,71 \\
3 & 1,23 & $63.819,6$ & 0,0 & $287.087,1$ & $13.363,6$ & 21,19 & 86,55 \\
4 & 1,25 & $83.560,4$ & 0,0 & $267.346,3$ & $13.363,6$ & 26,61 & 83,68 \\
5 & 1,43 & $83.560,4$ & $109.420,0$ & $157.926,3$ & $13.363,6$ & 56,65 & 77,07 \\
\hline
\end{tabular}

FONTE: Autoria própria.

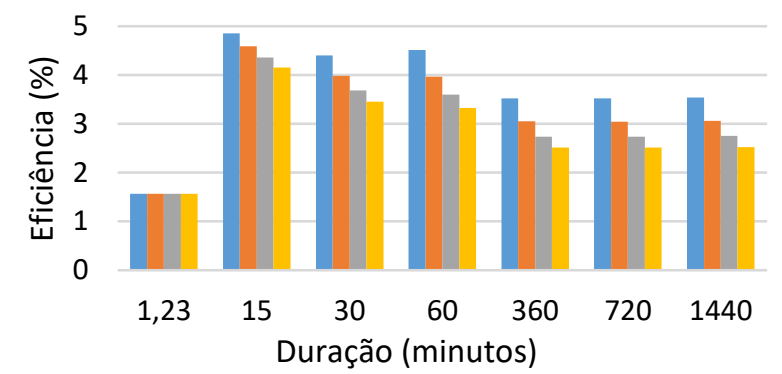

Tempo de retorno: $\square$ meses $\square$ anos $\square$ anos $\square 10$ anos

[a] cenário 3

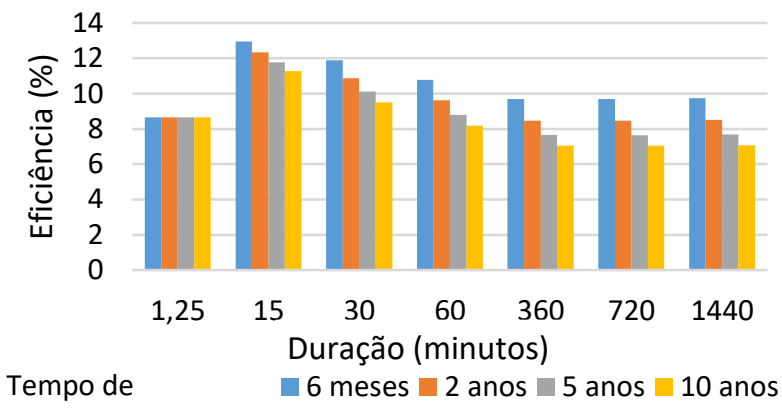

[b] cenário 4

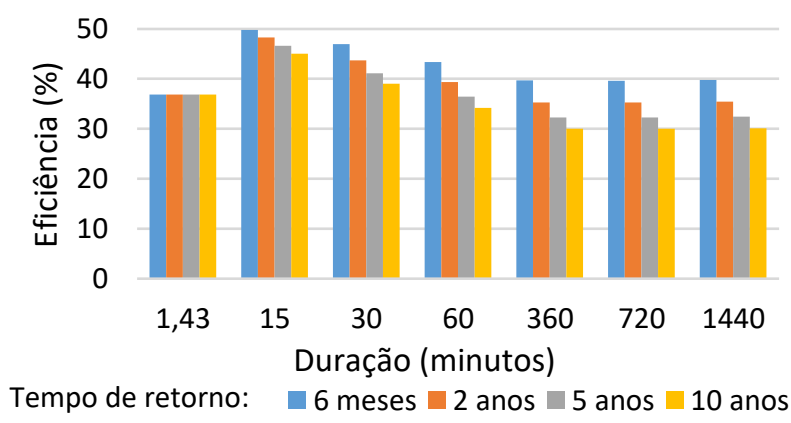

[c] cenário 5

FIGURA 3: Eficiência hidrológica em função da duração do evento e seu respectivo tempo de recorrência.

FONTE: Autoria própria.

Já no cenário 4, houve uma melhoria da efetividade dos sistemas de biorretenção devido ao aumento da área permeável mínima por lote, provocando valores da ordem de $12 \%$ para eventos de 15 minutos em todos os tempos de retorno simulados. No geral, apesar do aumento em relação ao cenário 3 , os valores continuaram baixos, e com pouca variação, de forma que em todos os eventos analisados, a eficiência fica em torno de 7 a $12 \%$, indicando conforme no cenário 3, um desempenho ruim devido à baixa área em relação à área impermeável do loteamento, porém mantendo uma constância independente da duração e intensidade do evento chuvoso. 
Para o cenário 5, torna-se claro, o grande aumento da eficiência hidrológica devido ao aumento da área permeável, através da inserção dos pavimentos permeáveis nas simulações. A eficiência máxima atingida foi de $49,84 \%$ para chuvas de 15 minutos de duração, com tempo de recorrência de 6 meses. A tendência de melhor desempenho em eventos curtos também foi verificada neste cenário. Para tempos de recorrência superiores e mesma duração, os valores também foram altos, ficando entre $45 \mathrm{e}$ $48 \%$.

Ainda sobre o cenário 5 , percebe-se também uma gradativa redução da eficiência em função do aumento da duração dos eventos chuvosos, mantendo o mesmo tempo de recorrência. Para eventos com duração igual ao tempo de concentração, a eficiência foi de $36,84 \%$ para todos os períodos de recorrência analisados, valor inferior aos aferidos para chuvas de 15 minutos, também consideradas curtas.

Outra análise importante é quanto à redução da vazão nas condições de maior eficiência de cada cenário. Através da Figura 4, nota-se que apesar da baixa eficiência encontrada para o cenário 4 , sendo o maior valor igual a 12,9 $\%$, a redução do escoamento ao longo do evento chuvoso é significativa, diminuindo até $2 \mathrm{~m}^{3} / \mathrm{s}$ durante o pico do escoamento, ou seja, aliviando as estruturas de drenagem convencionais justamente no momento em que estão mais solicitadas.

No cenário 5, a redução é ainda mais significativa, propiciando valores de vazão de pico inferiores a metade das vazões verificadas no cenário 2 , que representa a situação mais crítica da área de estudo, evidenciando a relação de proporcionalidade entre a área destinada às técnicas compensatórias e sua efetividade na redução do escoamento pluvial.

As equações da eficiência em função da precipitação para cada cenário analisado são apresentadas na Tabela 3. Evidencia-se o alto valor de $R^{2}$ obtido através da correlação entre as precipitações simuladas e os valores de eficiência obtidos, indicando uma boa representação dos dados através das equações apresentadas. Todas têm a restrição de serem aplicadas apenas às condições de umidade média do solo e para a área de estudo em questão.

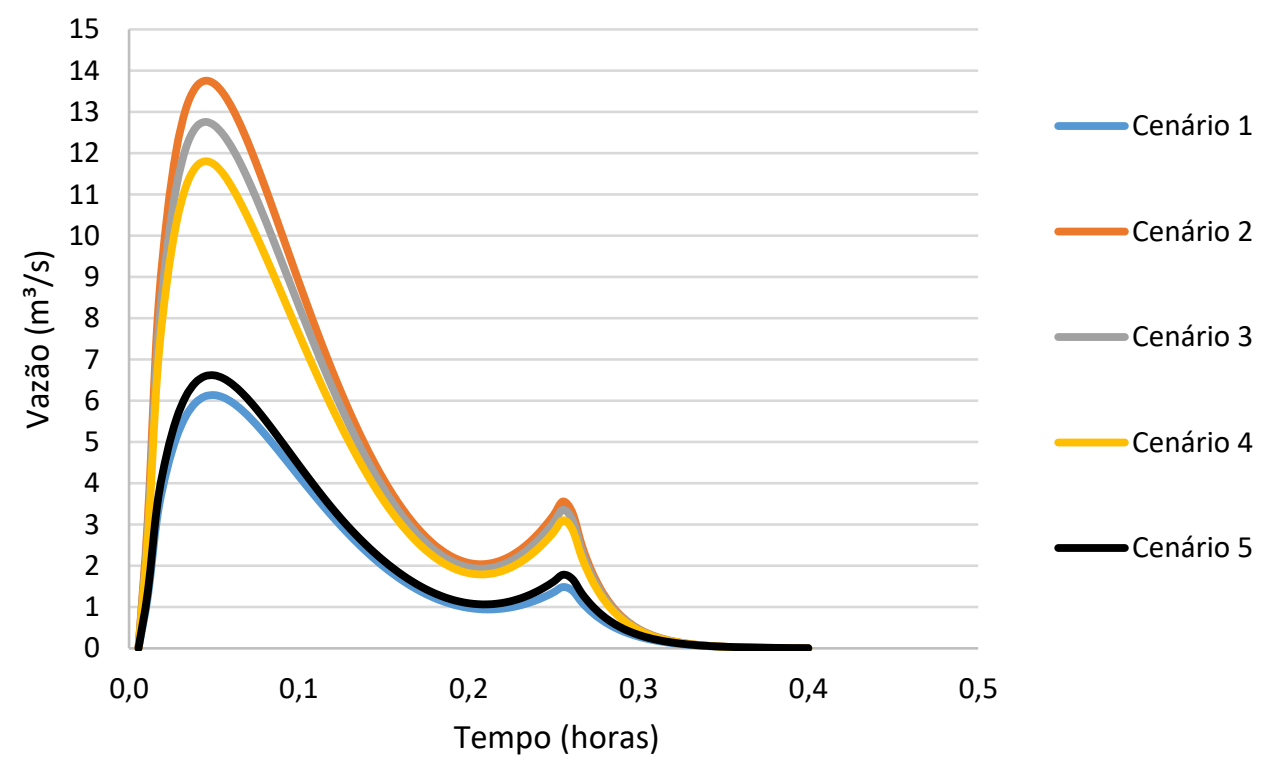

FIGURA 4 - Hidrograma para a situação de melhor eficiência dos cenários 4 e 5. Duração da chuva igual a 15 minutos e tempo de retorno de 6 meses.

FONTE: Autoria própria. 
TABELA 3 - Equações de eficiência (\%) em função da precipitação, com introdução de sistemas de biorretenção e alteração na área permeável mínima. Aplicável para 2,22 $\mathrm{mm} \leq \mathrm{P}(\mathrm{mm}) \leq 87,42 \mathrm{~mm}$.

Cenário e descrição
Equação

$E=4 \times 10-10 . P 6-1 \times 10-7 . P 5+9 \times 10-6 . P 4-0,0003 . P 3$

$+0,0058 \cdot P 2+0,3713 . P+0,2974$
$\mathbf{R}^{2}$

0,96 sistemas de biorretenção
$E=2 \times 10-8 . P 5-6 \times 10-6 . P 4+0,0007 . P 3-0,0372 . P 2+$

$0,8142 . P+6,5038$
0,98

Cenário 4 - Loteamento adensado + sistemas de biorretenção + aumento da área permeável mínima
Cenário 5 - Loteamento adensado + sistemas de biorretenção + aumento da área permeável mínima + pavimentos permeáveis
$E=5 \times 10-8 . P 5-2 \times 10-5 . P 4+0,0019 . P 3-0,107 . P 2+$

2,4117. $P+30,383$

\section{CONCLUSÕES}

Através dos resultados obtidos, conclui-se que as técnicas compensatórias são estratégias eficientes no manejo das águas pluviais, diminuindo a solicitação dos sistemas de drenagem convencionais e a probabilidade de sobrecarga dos mesmos.

Destacam-se também os benefícios da associação das técnicas compensatórias para a área de estudo, uma vez que os sistemas de biorretenção e os pavimentos permeáveis, trabalhando em conjunto, oferecem elevada eficiência hidrológica e consequente redução do escoamento.

Além disso, observa-se que a necessidade da revisão do valor da taxa de área permeável presente na legislação do município de Patrocínio, valor abaixo do utilizado por municípios vizinhos como Uberlândia e Patos de Minas, propiciando que problemas decorrentes da sobrecarga do sistema de drenagem, como enchentes e alagamentos, possam ocorrer mesmo sob chuvas com intensidades menores; o que poderia ser evitado caso fosse requerido um valor superior ao mínimo estabelecido

Verifica-se também para a área de estudo, uma maior dependência da existência de áreas em que são aplicadas as técnicas compensatórias do que em relação ao seu poder de retenção do escoamento. Isso comprova a importância do planejamento de um empreendimento ainda na fase de concepção do mesmo, projetando o tamanho de lotes, ruas, avenidas, e áreas de recreação (ou áreas verdes) de forma que elas consigam agregar valor ao loteamento, tanto com relação à parte urbanística, quanto na questão funcional do loteamento, no qual se insere a drenagem urbana.

Por fim, evidencia-se ainda o ganho paisagístico e sustentável que a área de estudo recebe com a aplicação de tais técnicas, propiciando uma melhor qualidade de vida para a população residente.

\section{AGRADECIMENTOS}

Fica registrado o apoio da Prefeitura de Patrocínio, que forneceu dados que auxiliaram na elaboração deste trabalho.

\section{REFERÊNCIAS BIBLIOGRÁFICAS}

ARAÚJO, P.R. et al. “Avaliação da eficiência dos pavimentos permeáveis na redução de escoamento superficial", in: Anais do IV Simpósio de Hidráulica e Recursos Hídricos dos Países de Língua Oficial Portuguesa - SILUSBA. Coimbra-Portugal. Lisboa: APRH, $1999 . \quad$ Disponível em: <http://www.iph.ufrgs.br/grad/disciplinas/dhh/iph0101 4/pavimentos.PDF>. Acesso em dez. 2018. 
AGOSTINHO, M. S. P.; POLETO, C. Sistemas Sustentáveis de Drenagem Urbana: Dispositivos. HOLUS Environment. Vol. 12, n. 2, p. 121, 2012. Disponível em: $<$ https://www.ceaunesp.org.br/holos/article/view/3054>. Acesso em: 28 nov. 2018.

ALAMY FILHO, J. E.; et al. Eficiência hidrológica de telhados verdes para a escala de loteamentos residenciais. Soc. \& Nat. Uberlândia. Vol. 28, n. 2, p. 257-272. mai/ago. 2016.

ARAÚJO, J. M. S. Avaliação da eficiência hidrológica por meio da implantação de técnicas compensatórias em loteamento urbano. Rio Paranaíba, 2018. 26 p.

ARAÚJO, P. R.; TUCCI, C. E. M.; GOLDENFUM, J. A., Avaliação da eficiência dos pavimentos permeáveis na redução do escoamento superficial. Revista Brasileira de Recursos Hídricos. Vol. 5, n. 3, p. 21-29. Jul/Set. 2000.

ASSOCIAÇÃO BRASILEIRA DE CIMENTO PORTLAND $(A B C P)$. Projeto técnico: pavimento permeável. Programa soluções para cidades. 2013. Disponível em: <http://www.solucoesparacidades.com.br/wpcontent/ uploads/2013/10/AF_Pav\%20Permeavel_web.pdf>. Acesso em dez. 2018.

ASSOCIAÇÃO BRASILEIRA DE NORMAS TÉCNICAS. NBR 9050. Acessibilidade a edificações, mobiliário, espaços e equipamentos urbanos. Rio de Janeiro, 2015, 148 p.

BAPTISTA, M; NASCIMENTO, N; BARRAUD, S. Técnicas compensatórias de drenagem urbana. $A B R H$, Porto Alegre, 2005.

BRASIL. Lei no 11.445, de 5 de janeiro de 2007. Estabelece diretrizes nacionais para o saneamento básico; altera as Leis $\mathrm{n}$ - 6.766, de 19 de dezembro de 1979, 8.036, de 11 de maio de 1990, 8.666, de 21 de junho de 1993, 8.987, de 13 de fevereiro de 1995; revoga a Lei no 6.528, de 11 de maio de 1978; e dá outras providências. Brasília DF, janeiro de 2007.

BROWN, R. A.; HUNT, W. F. Impacts of Media Depth on Effluent Water Quality and Hydrologic Performance of Undersized Bioretention Cells. Journal of Irrigation and Drainage Engineering. v. 137, n. 3, p. 132-143, 2011.

CADORE, R. C. Critérios de dimensionamento de biorretenções. Dissertação. Universidade Federal de Santa Maria. Centro de Tecnologia. Programa de PósGraduação em Engenharia Civil. 116p. 2016.

CARPENTER, D. D. Lid Design for Storm water management. Department of Environment Quality, Michigan State. Disponível em $<$ https://www.michigan.gov/documents/deq/Stormwat er_-

_Carpenter_LID_Design_for_SW_Management_49737 4_7.pdf>. Acesso em dez. 2018.
CIRIA. The SUDS manual. Department of Environment Food \& Rural Affairs. London. 968 p. 2015. Disponível em:

http://www.scotsnet.org.uk/documents/NRDG/CIRIAreport-C753-the-SuDS-manual-v6.pdf. Acessado em 2018.

CITY OF CHICAGO. A guide to stormwater best management practices. Chicago, Estados Unidos, 2003. 29 p. Disponível em: <https://www.cityofchicago.org/dam/city/depts/doe/g eneral/NaturalResourcesAndWaterConservation_PDFs/ Water/guideToStormwaterBMP.pdf.>Acesso em 2018.

CNT. Center for Neighborhood Technology. The Value of Green Infrastructure - A guide to recognizing its economic, environmental and social benefits, 2010. Disponível em: <http://www.cnt.org/repository/givalues-guide.pdf.> Acessado em 2018.

CORMIER, N. S.; PELLEGRINO, P. R. M. Infra-estrutura Verde: uma estratégia paisagística para a água urbana. Paisagem Ambiente: ensaios. n. 25. p. 127-142. 2008.

COSTA, A. R.; SIQUEIRA, E. Q.; MENEZES FILHO, F. C. M. Curso básico de hidrologia urbana: nível 3. ReCESA, Brasília, 2007. 130 p.

CRUZ, M. A. S.; SOUZA, C. F.: TUCCI, C. E. M. Controle de Drenagem Urbana no Brasil: Avanços e Mecanismos para sua Sustentabilidade. Simpósio Brasileiro de Recursos Hídricos, XVII, 2007, São Paulo. Disponível em: $<$ http://rhama.com.br/blog/wp-501 content/uploads/2017/04/controledrenagemurbana.pd f>. Acesso em: 28 nov. 2018.

DANIEL JÚNIOR, J. J. Avaliação de uma biorretenção como estrutura sustentável de drenagem urbana. Dissertação. Universidade Federal de Santa Maria. Centro de Tecnologia. Programa de Pós-Graduação em Engenharia Civil. 115 p. 2013.

DAVIS, A. P.; HUNT, W.F.; TRAVER, R. G.; CLAR, M. Bioretention Technology: Overview of Current Practice and Future Needs. Journal of Environmental Engineering. v. 135, n. 3, p. 109-117, 2009.

DEBUSK, K. M.; WYNN, T. M. Storm-Water Bioretention for Runoff Quality and Quantity Mitigation. Journal of Environmental Engineering, [s. I.], v. 137, n. 9, p. 800808,2011

ECKART, K.; MCPHEE, Z.; BOLISETTI, T. Performance and implementation of low impact development - A review. Science of the Total Environment. v. 607-608, p. 413-432, 2017. Disponível em: <http://dx.doi.org/10.1016/j.scitotenv.2017.06.254>. Acessado em nov. 2018.

EMPRESA BRASILEIRA DE PESQUISA AGROPECUÁRIA, Latossolos. Disponível em: < http://www.agencia.cnptia.embrapa.br/Agencia16/AG0 1/arvore/AG01_96_10112005101956.html>. Acesso em nov. 2018. 
GPRH. GRUPO DE PESQUISAS EM RECURSOS HÍDRICOS - UFV. Plúvio 2.1. Disponível em: $<w w w . g p r h . u f v . b r /$ ?area=softwares $>$. Acesso em nov. de 2018.

HUFF, F. A. Time distribution of rainfall in heavy storms. Water Resouces Research. vol. 3. n. 4. p.1007-1019. 1967.

HUNT W. F.; JARRET, A. R.; SMITH, J. T.; SHARKEY, L.J. Evaluating Bioretention Hydrology and Nutrient Removal at Three Field Sites in North Carolina. Journal of Irrigation and Drainage Engineering. v. 132. n. 6. p. 600-608. 2006.

HUNT, W. F.; SMITH, J. T.; JADLOCKI, S. J.; HATHAWAY, J.M.; EUBANKS, P.R. Pollutant Removal and Peak Flow Mitigation by a Bioretention Cell in Urban Charlotte, N.C. Journal of Environmental Engineering. v. 134. n. 5. p. 403-408. 2008.99

INSTITUTO AGRONÔMICO DE SÃO PAULO (IAC). Latossolos. Disponível em: < http://www.iac.sp.gov.br/solossp/pdf/Latossolos.pdf>. Acesso em nov. 2018.

INSTITUTO BRASILEIRO DE GEOGRAFIA ESTATÍSTICA.
Patrocínio. <https://cidades.ibge.gov.br/brasil/mg/patrocinio/pano rama>. Acessado em 2018.

JUNIOR, J. A. O.; MALAVOLTA, E.; CABRAL C. P. Efeitos do Manganês sobre a soja cultivada em solo do cerrado do triângulo mineiro. Pesquisa agropecuária brasileira, Brasília, v.35, n.8, p.1629-1636, ago. 2000

MAUS, V. W.; RIGHES, A. A.; BURIOL, G. A. Pavimentos permeáveis e escoamento superficial em áreas urbanas. In: I SIMPÓSIO DE RECURSOS HÍDRICOS DO NORTE E CENTRO-OESTE. 2007. Cuiabá.

MELO, T. dos A. T. DE; COUTINHO, A. P.; CABRAL, J. J. da S. P.; ANTONINO, A. C. D.; CIRILO, J. A. Jardim de chuva: sistema de biorretenção para o manejo das águas pluviais urbanas. Ambiente Construído, Porto Alegre, v. 14, n. 4, p. 147-165, out. /dez. 2014.

MELO, T. A. T.; COUTINHO, A. P.; CABRAL, J. J. S. P. Manejo de águas pluviais através de um sistema de biorretenção. In: XXI SIMPÓSIO BRASILEIRO DE RECURSOS HÍDRICOS. 2015, Brasília.

METHODS, H; DURRANS, S. R. Stormwater conveyance modeling and design. First Edition. Waterbury, USA: Haestad Press, 2003.

MIGUEZ, M. G; VERÓL, A. P; REZENDE, O. M. Drenagem urbana: do projeto tradicional à sustentabilidade. 1을 ed. - Rio de Janeiro: Elsevier. 2016.
MOURA, N. C. B. Biorretenção -Tecnologia ambiental urbana para manejo das águas de chuva. Tese (Doutorado em arquitetura). Universidade de São Paulo. 299 p. 2013.

NASCIMENTO, R. C. O uso do biofertilizante em solos agrícolas do cerrado da região do alto Paranaíba (MG). Boletim goiano de geografia. Goiânia, v. 30, n. 2, p. 5566, jul./dez. 2010

PATOS DE MINAS. Lei complementar № 320 do município de Patos de Minas, de 31 de dezembro de 2008. Institui a revisão da lei de zoneamento, uso e ocupação dos terrenos e edificações no município de Patos de Minas. Patos de Minas, dezembro de 2008. Disponível em:

https://leismunicipais.com.br/a/mg/p/patos-deminas/lei-complementar/2008/32/320/leicomplementar-n-320-2008-institui-a-revisao-da-lei-dezoneamento-uso-e-ocupacao-dos-terrenos-eedificacoes-no-municipio-de-patos-de-minas. em: out. 2018.

PATROCÍNIO. Lei complementar № 131 do município de Patrocínio, de 04 de dezembro de 2014. Dispõe sobre o parcelamento do solo urbano do município de patrocínio e dá outras providências. Patrocínio MG, dezembro de $2014 . \quad$ Disponível em: https://portal.patrocinio.mg.gov.br/pmp/index.php/pu blicacoes/urbanismo. Acesso em: nov. 2018.

Lei complementar № 132 do município de Patrocínio, de 03 de dezembro de 2014. Dispõe sobre o zoneamento, o uso e a ocupação do solo no município de patrocínio e dá outras providências. Patrocínio MG, dezembro de 2014. Disponível em: https://portal.patrocinio.mg.gov.br/pmp/index.php/pu blicacoes/urbanismo. Acesso em: nov. 2018.

Plano municipal de Saneamento básico. Produto 6 - relatório do plano municipal de saneamento básico. Patrocínio, MG, 2016. Disponível em:

https://portal.patrocinio.mg.gov.br/pmp/index.php/pu blicacoes/urbanismo. Acesso em: nov. 2018.

PAUS, K.; BRASKERUD, B. Suggestions for Designing and Constructing Bioretention Cells for a Nordic Climate. Journal of Water Management and Research. v. 70. p. 139-150. Lund. 2014.

PINTO, L. L. C. A. O Desempenho de Pavimentos Permeáveis Como Medida Mitigadora da Impermeabilização do Solo Urbano. Tese (Doutorado). Escola Politécnica, Universidade de São Paulo, São Paulo, 2011. 255 p. 
PHILIPPI. JR, A. Saneamento, Saúde e Ambiente: Fundamentos para um desenvolvimento sustentável. 1. ed. Barueri, SP. Manole, 2005.

PRINCE GEOGE'S COUNTY, MARYLAND - DEPARTMENT OF ENVIRONMENTAL RESOURCES. Bioretention Manual. Prince George's county, Maryland, 2007. 206 p. Disponível em: <http://www.ct.gov/deep/lib/deep/p2/raingardens/bio retention_manual_2009_version.pdf.> Acessado em 2018.

ROY-POIRIER, A.; CHAMPAGNE, P.; FILION, Y. Review of Bioretention system research and design: Past, presente and future. Journal of environmental engineering. V. 136, N. 9, p. 878-889. 2010.

SOUSA, J. S. Áreas de preservação permanente urbanas, mapeamento, diagnósticos, índices de qualidade ambiental e influência no escoamento superficial, Tese de Doutorado, FECIV/UFU, Uberlândia, MG, jul. de 2008.

SOUZA, V. C. B. Gestão da drenagem urbana no Brasil: Desafios para a sustentabilidade. Revista eletrônica de gestão e tecnologias ambientas (GESTA). V. 1, n.1, p. 57 72. 2013

STUBCHAER, J.M. The Santa Barbara urban hydrograph method. Proceedings of the National Symposium of Hydrology and Sediment Control, Lexington, New York, USA, 1980.

TUCCI, C. E. M. (org.). Hidrologia ciência e aplicação. 3 ed. Porto Alegre, RS: Editora da UFRGS/ABRH, 2004. 943p.

TUCCI, C. E. Inundações Urbanas. Coleção ABRH de Recursos Hídricos, V. 11.1 ed. Porto Alegre: ABRH/RHAMA, 2007.393 p.

TUCCI, C. E. M.; MELLER, A. Regulação das águas pluviais urbanas. Rega - Revista de Gestão da América Latina, Porto Alegre: v. 4, n. 1, p. 75 - 89, 2007.

UBERLÂNDIA, Lei complementar № $\mathbf{5 2 5}$ do município de Uberlândia, de 14 de abril de 2011. Dispõe sobre o zoneamento do uso e ocupação do solo do município de Uberlândia e revoga a lei complementar $\mathrm{n}$ ㅇ, de 30 de novembro de 2000 e suas alterações posteriores. Uberlandia, abril de 2011. Disponível em: https://leismunicipais.com.br/a1/plano-dezoneamento-uso-e-ocupacao-do-solo-uberlandia-mg. Acesso em: out. 2018.

UNHSC. University of New Hampshire Stormwater Center. 2005 Data Report. 2005. Disponível em: https://www.unh.edu/unhsc/sites/unh.edu.unhsc/files/ pubs_specs_info/annual_data_report_06.pdf.>.

Acessado em 2018.
UNITED STATES ENVIRONMENTAL PROTECTION AGENCY (USEPA). Preliminary data summary of urban storm water best management practices. Washington, EUA. 214 p. 1999.

WARDYNSKI, B. J.; HUNT, W. F. Are Bioretention Cells Being Installed Per Design Standards in North Carolina? A Field Study. Journal of environmental engineering. v. 138. n. 12. p. 1210-1217. 2012.

ZHOU, Q. A review of sustainable urban drainage systems considering the climate change and urbanization impacts. Journal Water. V. 6 p. 976992. 2014. 
DOCUMENTAÇÃO SUPLEMENTAR

\section{APÊNDICE A - Resultados de vazão e volume escoado para cada simulação}

\section{Tabela A1 - Resultados para Cenário 1}

\begin{tabular}{|c|c|c|c|c|c|c|c|c|c|c|c|c|c|c|}
\hline \multicolumn{15}{|c|}{ Tempo de duração } \\
\hline \multirow{2}{*}{$\begin{array}{l}\text { Período } \\
\text { de } \\
\text { retorno } \\
\text { (anos) }\end{array}$} & \multicolumn{2}{|c|}{$\mathrm{tc}=1,47 \mathrm{~min}$} & \multicolumn{2}{|c|}{$15 \mathrm{~min}}$. & \multicolumn{2}{|c|}{$30 \mathrm{~min}}$. & \multicolumn{2}{|c|}{$60 \mathrm{~min}}$. & \multicolumn{2}{|c|}{360 (6 horas) } & \multicolumn{2}{|c|}{720 min. (12 horas) } & \multicolumn{2}{|c|}{$1440 \mathrm{~min}$. (24 horas) } \\
\hline & $\begin{array}{l}\text { Vazão } \\
\text { de } \\
\text { pico } \\
\left(\mathrm{m}^{3} / \mathrm{s}\right)\end{array}$ & $\begin{array}{c}\text { Volume } \\
\text { escoado } \\
\left(\mathrm{m}^{3}\right)\end{array}$ & $\begin{array}{l}\text { Vazão } \\
\text { de } \\
\text { pico } \\
\left(\mathrm{m}^{3} / \mathrm{s}\right)\end{array}$ & $\begin{array}{c}\text { Volume } \\
\text { escoado } \\
\left(\mathrm{m}^{3}\right)\end{array}$ & $\begin{array}{l}\text { Vazão } \\
\text { de } \\
\text { pico } \\
\left(\mathrm{m}^{3} / \mathrm{s}\right)\end{array}$ & $\begin{array}{c}\text { Volume } \\
\text { escoado } \\
\left(\mathrm{m}^{3}\right)\end{array}$ & $\begin{array}{l}\text { Vazão } \\
\text { de } \\
\text { pico } \\
\left(\mathrm{m}^{3} / \mathrm{s}\right)\end{array}$ & $\begin{array}{c}\text { Volume } \\
\text { escoado } \\
\left(\mathrm{m}^{3}\right)\end{array}$ & $\begin{array}{l}\text { Vazão } \\
\text { de } \\
\text { pico } \\
\left(\mathrm{m}^{3} / \mathrm{s}\right)\end{array}$ & $\begin{array}{c}\text { Volume } \\
\text { escoado } \\
\left(\mathrm{m}^{3}\right)\end{array}$ & $\begin{array}{l}\text { Vazão } \\
\text { de pico } \\
\left(\mathrm{m}^{3} / \mathrm{s}\right)\end{array}$ & $\begin{array}{c}\text { Volume } \\
\text { escoado } \\
\left(\mathrm{m}^{3}\right)\end{array}$ & $\begin{array}{l}\text { Vazão } \\
\text { de pico } \\
\left(\mathrm{m}^{3} / \mathrm{s}\right)\end{array}$ & $\begin{array}{c}\text { Volume } \\
\text { escoado } \\
\left(\mathrm{m}^{3}\right)\end{array}$ \\
\hline 0,5 & 2,59 & 343,6 & 6,18 & 2827,5 & 5,57 & 4279,7 & 4,17 & 5928,4 & 0,59 & 8101,3 & 0,30 & 8149,3 & 0,19 & 7984,1 \\
\hline 2 & 3,38 & 447,7 & 8,05 & 3684,7 & 7,25 & 5783,1 & 5,44 & 8260,4 & 0,90 & 11475,0 & 0,45 & 11542,3 & 0,28 & 11305,5 \\
\hline 5 & 4,02 & 533,3 & 9,59 & 4418,2 & 8,64 & 7173,7 & 6,48 & 10390,6 & 1,18 & 14518,1 & 0,59 & 14601,8 & 0,37 & 14303,3 \\
\hline 10 & 4,59 & 608,8 & 10,95 & 5124,4 & 9,86 & 8498,8 & 7,40 & 12400,5 & 1,43 & 17362,4 & 0,72 & 17460,9 & 0,45 & 17106,6 \\
\hline
\end{tabular}

\section{Tabela A2 - Resultados para Cenário 2}

\begin{tabular}{|c|c|c|c|c|c|c|c|c|c|c|c|c|c|c|}
\hline \multicolumn{15}{|c|}{ Tempo de duração } \\
\hline \multirow{2}{*}{$\begin{array}{l}\text { Período } \\
\text { de } \\
\text { retorno } \\
\text { (anos) }\end{array}$} & \multicolumn{2}{|c|}{$\mathrm{tc}=1,21 \mathrm{~min}}$. & \multicolumn{2}{|c|}{$15 \mathrm{~min}}$. & \multicolumn{2}{|c|}{$30 \mathrm{~min}}$. & \multicolumn{2}{|c|}{$60 \mathrm{~min}}$. & \multicolumn{2}{|c|}{$360 \mathrm{~min}$. ( 6 horas) } & \multicolumn{2}{|c|}{$720 \mathrm{~min}$. (12 horas) } & \multicolumn{2}{|c|}{$1440 \mathrm{~min}$. ( 24 horas) } \\
\hline & $\begin{array}{c}\text { Vazão } \\
\text { de } \\
\text { pico } \\
\left(\mathrm{m}^{3} / \mathrm{s}\right)\end{array}$ & $\begin{array}{c}\text { Volume } \\
\text { escoado } \\
\left(\mathrm{m}^{3}\right)\end{array}$ & $\begin{array}{l}\text { Vazão } \\
\text { de } \\
\text { pico } \\
\left(\mathrm{m}^{3} / \mathrm{s}\right)\end{array}$ & $\begin{array}{c}\text { Volume } \\
\text { escoado } \\
\left(\mathrm{m}^{3}\right)\end{array}$ & $\begin{array}{l}\text { Vazão } \\
\text { de } \\
\text { pico } \\
\left(\mathrm{m}^{3} / \mathrm{s}\right)\end{array}$ & $\begin{array}{c}\text { Volume } \\
\text { escoado } \\
\left(\mathrm{m}^{3}\right)\end{array}$ & $\begin{array}{l}\text { Vazão } \\
\text { de } \\
\text { pico } \\
\left(\mathrm{m}^{3} / \mathrm{s}\right)\end{array}$ & $\begin{array}{c}\text { Volume } \\
\text { escoado } \\
\left(\mathrm{m}^{3}\right)\end{array}$ & $\begin{array}{l}\text { Vazão } \\
\text { de } \\
\text { pico } \\
\left(\mathrm{m}^{3} / \mathrm{s}\right)\end{array}$ & $\begin{array}{c}\text { Volume } \\
\text { escoado } \\
\left(\mathrm{m}^{3}\right)\end{array}$ & $\begin{array}{l}\text { Vazão } \\
\text { de pico } \\
\left(\mathrm{m}^{3} / \mathrm{s}\right)\end{array}$ & $\begin{array}{c}\text { Volume } \\
\text { escoado } \\
\left(\mathrm{m}^{3}\right)\end{array}$ & $\begin{array}{l}\text { Vazão } \\
\text { de pico } \\
\left(\mathrm{m}^{3} / \mathrm{s}\right)\end{array}$ & $\begin{array}{l}\text { Volume } \\
\text { escoado } \\
\left(\mathrm{m}^{3}\right)\end{array}$ \\
\hline 0,5 & 5,28 & 562,4 & 13,58 & 6086,6 & 12,04 & 9419,7 & 8,88 & 12769,6 & 1,39 & 16662,8 & 0,70 & 16752,0 & 0,40 & 16455,8 \\
\hline 2 & 6,89 & 732,9 & 17,89 & 8066,6 & 15,93 & 12491,8 & 11,72 & 16921,1 & 1,85 & 22051,8 & 0,93 & 22168,6 & 0,52 & 21779,7 \\
\hline 5 & 8,20 & 873,1 & 21,54 & 9721,4 & 19,22 & 15048,9 & 14,14 & 20366,8 & 2,23 & 26514,6 & 1,12 & 26654,1 & 0,63 & 26189,1 \\
\hline 10 & 9,36 & 996,7 & 24,82 & 11195,3 & 22,17 & 17320,1 & 16,32 & 23421,5 & 2,57 & 30465,2 & 1,29 & 30624,7 & 0,72 & 30092,8 \\
\hline
\end{tabular}

Tabela A3 - Resultados para Cenário 3

\begin{tabular}{|c|c|c|c|c|c|c|c|c|c|c|c|c|c|c|}
\hline \multicolumn{15}{|c|}{ Tempo de duração } \\
\hline \multirow{2}{*}{$\begin{array}{l}\text { Período } \\
\text { de } \\
\text { retorno } \\
\text { (anos) }\end{array}$} & \multicolumn{2}{|c|}{$\mathrm{tc}=1,23 \mathrm{~min}}$. & \multicolumn{2}{|c|}{$15 \mathrm{~min}}$. & \multicolumn{2}{|c|}{$30 \mathrm{~min}}$. & \multicolumn{2}{|c|}{$60 \mathrm{~min}}$. & \multicolumn{2}{|c|}{$360 \mathrm{~min}$. (6 horas) } & \multicolumn{2}{|c|}{$720 \mathrm{~min}$. (12 horas) } & \multicolumn{2}{|c|}{$1440 \mathrm{~min}$. (24 horas) } \\
\hline & $\begin{array}{c}\text { Vazão } \\
\text { de } \\
\text { pico } \\
\left(\mathrm{m}^{3} / \mathrm{s}\right)\end{array}$ & $\begin{array}{c}\text { Volume } \\
\text { escoado } \\
\left(\mathrm{m}^{3}\right)\end{array}$ & $\begin{array}{c}\text { Vazão } \\
\text { de } \\
\text { pico } \\
\left(\mathrm{m}^{3} / \mathrm{s}\right)\end{array}$ & $\begin{array}{c}\text { Volume } \\
\text { escoado } \\
\left(\mathrm{m}^{3}\right)\end{array}$ & $\begin{array}{l}\text { Vazão } \\
\text { de } \\
\text { pico } \\
\left(\mathrm{m}^{3} / \mathrm{s}\right)\end{array}$ & $\begin{array}{c}\text { Volume } \\
\text { escoado } \\
\left(\mathrm{m}^{3}\right)\end{array}$ & $\begin{array}{l}\text { Vazão } \\
\text { de } \\
\text { pico } \\
\left(\mathrm{m}^{3} / \mathrm{s}\right)\end{array}$ & $\begin{array}{c}\text { Volume } \\
\text { escoado } \\
\left(\mathrm{m}^{3}\right)\end{array}$ & $\begin{array}{l}\text { Vazão } \\
\text { de } \\
\text { pico } \\
\left(\mathrm{m}^{3} / \mathrm{s}\right)\end{array}$ & $\begin{array}{c}\text { Volume } \\
\text { escoado } \\
\left(\mathrm{m}^{3}\right)\end{array}$ & $\begin{array}{l}\text { Vazão } \\
\text { de pico } \\
\left(\mathrm{m}^{3} / \mathrm{s}\right)\end{array}$ & $\begin{array}{c}\text { Volume } \\
\text { escoado } \\
\left(\mathrm{m}^{3}\right)\end{array}$ & $\begin{array}{l}\text { Vazão } \\
\text { de pico } \\
\left(\mathrm{m}^{3} / \mathrm{s}\right)\end{array}$ & $\begin{array}{c}\text { Volume } \\
\text { escoado } \\
\left(\mathrm{m}^{3}\right)\end{array}$ \\
\hline 0,5 & 5,03 & 553,6 & 12,88 & 5790,9 & 11,41 & 9005,4 & 8,38 & 12193,5 & 1,34 & 16075,5 & 0,67 & 16161,9 & 0,38 & 15873,4 \\
\hline 2 & 6,56 & 721,4 & 16,89 & 7696,4 & 15,05 & 11993,7 & 10,97 & 16250,1 & 1,79 & 21379,3 & 0,90 & 21492,8 & 0,51 & 21112,6 \\
\hline 5 & 7,81 & 859,4 & 20,34 & 9297,9 & 18,18 & 14494,0 & 13,25 & 19634,1 & 2,17 & 25788,0 & 1,09 & 25923,8 & 0,62 & 25468,2 \\
\hline 10 & 8,92 & 981,0 & 23,46 & 10730,1 & 21,00 & 16722,2 & 15,33 & 22643,2 & 2,51 & 29699,5 & 1,26 & 29854,8 & 0,71 & 29332,8 \\
\hline
\end{tabular}


Tabela A4 - Resultados para Cenário 4

\begin{tabular}{|c|c|c|c|c|c|c|c|c|c|c|c|c|c|c|}
\hline \multicolumn{15}{|c|}{ Tempo de duração } \\
\hline \multirow{2}{*}{$\begin{array}{l}\text { Período } \\
\text { de } \\
\text { retorno } \\
\text { (anos) }\end{array}$} & \multicolumn{2}{|c|}{$\mathrm{tc}=1,25 \mathrm{~min}}$. & \multicolumn{2}{|c|}{$15 \mathrm{~min}}$. & \multicolumn{2}{|c|}{$30 \mathrm{~min}}$. & \multicolumn{2}{|c|}{$60 \mathrm{~min}}$. & \multicolumn{2}{|c|}{$360 \mathrm{~min}$. ( 6 horas) } & \multicolumn{2}{|c|}{720 min. (12 horas) } & \multicolumn{2}{|c|}{$1440 \mathrm{~min}$. ( 24 horas) } \\
\hline & $\begin{array}{l}\text { Vazão } \\
\text { de } \\
\text { pico } \\
\left(\mathrm{m}^{3} / \mathrm{s}\right)\end{array}$ & $\begin{array}{c}\text { Volume } \\
\text { escoado } \\
\left(\mathrm{m}^{3}\right)\end{array}$ & $\begin{array}{l}\text { Vazão } \\
\text { de } \\
\text { pico } \\
\left(\mathrm{m}^{3} / \mathrm{s}\right)\end{array}$ & $\begin{array}{c}\text { Volume } \\
\text { escoado } \\
\left(\mathrm{m}^{3}\right)\end{array}$ & $\begin{array}{l}\text { Vazão } \\
\text { de } \\
\text { pico } \\
\left(\mathrm{m}^{3} / \mathrm{s}\right)\end{array}$ & $\begin{array}{c}\text { Volume } \\
\text { escoado } \\
\left(\mathrm{m}^{3}\right)\end{array}$ & $\begin{array}{l}\text { Vazão } \\
\text { de } \\
\text { pico } \\
\left(\mathrm{m}^{3} / \mathrm{s}\right)\end{array}$ & $\begin{array}{c}\text { Volume } \\
\text { escoado } \\
\left(\mathrm{m}^{3}\right)\end{array}$ & $\begin{array}{l}\text { Vazão } \\
\text { de } \\
\text { pico } \\
\left(\mathrm{m}^{3} / \mathrm{s}\right)\end{array}$ & $\begin{array}{c}\text { Volume } \\
\text { escoado } \\
\left(\mathrm{m}^{3}\right)\end{array}$ & $\begin{array}{c}\text { Vazão } \\
\text { de pico } \\
\left(\mathrm{m}^{3} / \mathrm{s}\right)\end{array}$ & $\begin{array}{c}\text { Volume } \\
\text { escoado } \\
\left(\mathrm{m}^{3}\right)\end{array}$ & $\begin{array}{l}\text { Vazão } \\
\text { de pico } \\
\left(\mathrm{m}^{3} / \mathrm{s}\right)\end{array}$ & $\begin{array}{c}\text { Volume } \\
\text { escoado } \\
\left(\mathrm{m}^{3}\right)\end{array}$ \\
\hline 0,5 & 4,62 & 513,7 & 11,80 & 5298,9 & 10,47 & 8300,8 & 7,77 & 11392,7 & 1,25 & 15047,3 & 0,63 & 15128,8 & 0,36 & 14854,1 \\
\hline 2 & 6,01 & 669,4 & 15,38 & 7071,5 & 13,67 & 11134,1 & 10,13 & 15294,8 & 1,69 & 20185,1 & 0,85 & 20292,8 & 0,49 & 19928,1 \\
\hline 5 & 7,17 & 797,5 & 18,44 & 8576,6 & 16,49 & 13527,2 & 12,12 & 18575,1 & 2,06 & 24486,0 & 1,03 & 24615,2 & 0,59 & 24176,5 \\
\hline 10 & 8,18 & 910,4 & 21,29 & 9932,0 & 19,09 & 15673,0 & 14,05 & 21506,4 & 2,39 & 28318,1 & 1,20 & 28466,3 & 0,69 & 27962,3 \\
\hline
\end{tabular}

Tabela A5 - Resultados para Cenário 5

Tempo de duração

\begin{tabular}{|c|c|c|c|c|c|c|c|c|c|c|c|c|c|c|}
\hline \multirow{2}{*}{$\begin{array}{l}\begin{array}{c}\text { Período } \\
\text { de }\end{array} \\
\text { retorno } \\
\text { (anos) }\end{array}$} & \multicolumn{2}{|c|}{$\mathrm{tc}=1,43 \mathrm{~min}}$. & \multicolumn{2}{|c|}{$15 \mathrm{~min}}$. & \multicolumn{2}{|c|}{$30 \mathrm{~min}$. } & \multicolumn{2}{|c|}{$60 \mathrm{~min}}$. & \multicolumn{2}{|c|}{$360 \mathrm{~min}$. (6 horas) } & \multicolumn{2}{|c|}{$720 \mathrm{~min}$. (12 horas) } & \multicolumn{2}{|c|}{$1440 \mathrm{~min}$. (24 horas) } \\
\hline & $\begin{array}{l}\text { Vazão } \\
\text { de } \\
\text { pico } \\
\left(\mathrm{m}^{3} / \mathrm{s}\right)\end{array}$ & $\begin{array}{c}\text { Volume } \\
\text { escoado } \\
\left(\mathrm{m}^{3}\right)\end{array}$ & $\begin{array}{l}\text { Vazão } \\
\text { de } \\
\text { pico } \\
\left(\mathrm{m}^{3} / \mathrm{s}\right)\end{array}$ & $\begin{array}{c}\text { Volume } \\
\text { escoado } \\
\left(\mathrm{m}^{3}\right)\end{array}$ & $\begin{array}{c}\text { Vazão } \\
\text { de } \\
\text { pico } \\
\left(\mathrm{m}^{3} / \mathrm{s}\right)\end{array}$ & $\begin{array}{c}\text { Volume } \\
\text { escoado } \\
\left(\mathrm{m}^{3}\right)\end{array}$ & $\begin{array}{l}\text { Vazão } \\
\text { de } \\
\text { pico } \\
\left(\mathrm{m}^{3} / \mathrm{s}\right)\end{array}$ & $\begin{array}{c}\text { Volume } \\
\text { escoado } \\
\left(\mathrm{m}^{3}\right)\end{array}$ & $\begin{array}{c}\text { Vazão } \\
\text { de } \\
\text { pico } \\
\left(\mathrm{m}^{3} / \mathrm{s}\right)\end{array}$ & $\begin{array}{c}\text { Volume } \\
\text { escoado } \\
\left(\mathrm{m}^{3}\right)\end{array}$ & $\begin{array}{l}\text { Vazão } \\
\text { de pico } \\
\left(\mathrm{m}^{3} / \mathrm{s}\right)\end{array}$ & $\begin{array}{c}\text { Volume } \\
\text { escoado } \\
\left(\mathrm{m}^{3}\right)\end{array}$ & $\begin{array}{c}\text { Vazão } \\
\text { de pico } \\
\left(\mathrm{m}^{3} / \mathrm{s}\right)\end{array}$ & $\begin{array}{c}\text { Volume } \\
\text { escoado } \\
\left(\mathrm{m}^{3}\right)\end{array}$ \\
\hline 0,5 & 2,74 & 355,2 & 6,62 & 3052,8 & 5,94 & 4999,3 & 4,45 & 7228,5 & 0,82 & 10050,9 & 0,41 & 10108,0 & 0,26 & 9904,6 \\
\hline 2 & 3,58 & 462,9 & 8,62 & 4170,6 & 7,75 & 7035,4 & 5,80 & 10257,2 & 1,20 & 14269,8 & 0,60 & 14348,1 & 0,37 & 14065,1 \\
\hline 5 & 4,26 & 551,5 & 10,27 & 5190,2 & 9,23 & 8860,8 & 6,85 & 12935,0 & 1,54 & 17954,0 & 0,77 & 18050,0 & 0,47 & 17700,3 \\
\hline 10 & 4,86 & 629,5 & 11,73 & 6152,6 & 10,79 & 10560,6 & 8,32 & 15403,7 & 1,84 & 21321,8 & 0,92 & 21433,4 & 0,56 & 21024,5 \\
\hline
\end{tabular}


APÊNDICE B - Resultados da eficiência hidrológica para cada cenário final

Tabela B1 - Eficiência (\%) - Cenário 3

\begin{tabular}{cccccccc} 
Período & \multicolumn{7}{c}{ Tempo de duração } \\
\cline { 2 - 7 } $\begin{array}{c}\text { de retorno } \\
\text { (anos) }\end{array}$ & $\mathbf{1 , 2 3}$ min. & $\mathbf{1 5} \mathbf{m i n}$. & $\mathbf{3 0}$ min. & $\mathbf{6 0}$ min. & $\mathbf{6}$ horas & $\mathbf{1 2}$ horas & $\mathbf{2 4}$ horas \\
\hline 0,5 & 1,57 & 4,86 & 4,40 & 4,51 & 3,52 & 3,52 & 3,54 \\
2 & 1,57 & 4,59 & 3,99 & 3,97 & 3,05 & 3,05 & 3,06 \\
5 & 1,57 & 4,36 & 3,69 & 3,60 & 2,74 & 2,74 & 2,75 \\
10 & 1,57 & 4,16 & 3,45 & 3,32 & 2,51 & 2,51 & 2,53
\end{tabular}

Tabela B2 - Eficiência (\%) - Cenário 4

\section{Período}

Tempo de duração

\begin{tabular}{crrrrrrr}
$\begin{array}{c}\text { de retorno } \\
\text { (anos) }\end{array}$ & $\mathbf{1 , 2 5} \mathbf{m i n}$. & $\mathbf{1 5} \mathbf{~ m i n .}$ & $\mathbf{3 0} \mathbf{m i n}$. & $\mathbf{6 0} \mathbf{~ m i n}$. & $\mathbf{6}$ horas & $\mathbf{1 2}$ horas & $\mathbf{2 4}$ horas \\
\hline 0,5 & 8,66 & 12,94 & 11,88 & 10,78 & 9,70 & 9,69 & 9,73 \\
2 & 8,66 & 12,34 & 10,87 & 9,61 & 8,46 & 8,46 & 8,50 \\
5 & 8,66 & 11,78 & 10,11 & 8,80 & 7,65 & 7,65 & 7,69 \\
10 & 8,66 & 11,28 & 9,51 & 8,18 & 7,05 & 7,05 & 7,08 \\
\hline
\end{tabular}

\section{Tabela B3 - Eficiência (\%) - Cenário 5}

\section{Período}

Tempo de duração de retorno

(anos) 1,43 min. $15 \mathrm{~min} . \quad 30 \mathrm{~min} . \quad 60 \mathrm{~min} .6$ horas 12 horas 24 horas

\begin{tabular}{rrrrrrrr}
\hline 0,5 & 36,84 & 49,84 & 46,93 & 43,39 & 39,68 & 39,66 & 39,81 \\
2 & 36,84 & 48,30 & 43,68 & 39,38 & 35,29 & 35,28 & 35,42 \\
5 & 36,84 & 46,61 & 41,12 & 36,49 & 32,29 & 32,28 & 32,41 \\
10 & 36,84 & 45,04 & 39,03 & 34,23 & 30,01 & 30,01 & 30,13 \\
\hline
\end{tabular}


APÊNDICE C - Hidrogramas para maiores e menores eficiências dos cenários finais

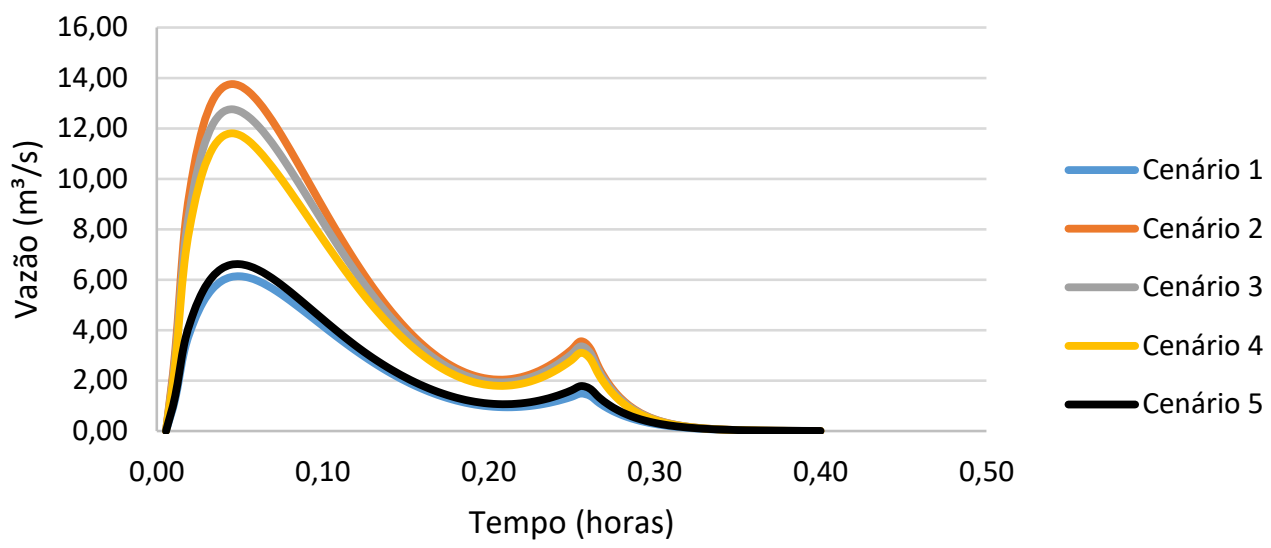

Figura C1 - Hidrograma para condição de maior eficiência para os cenários 3, 4 e 5. Duração 15 min. Tempo de retorno 6 meses.

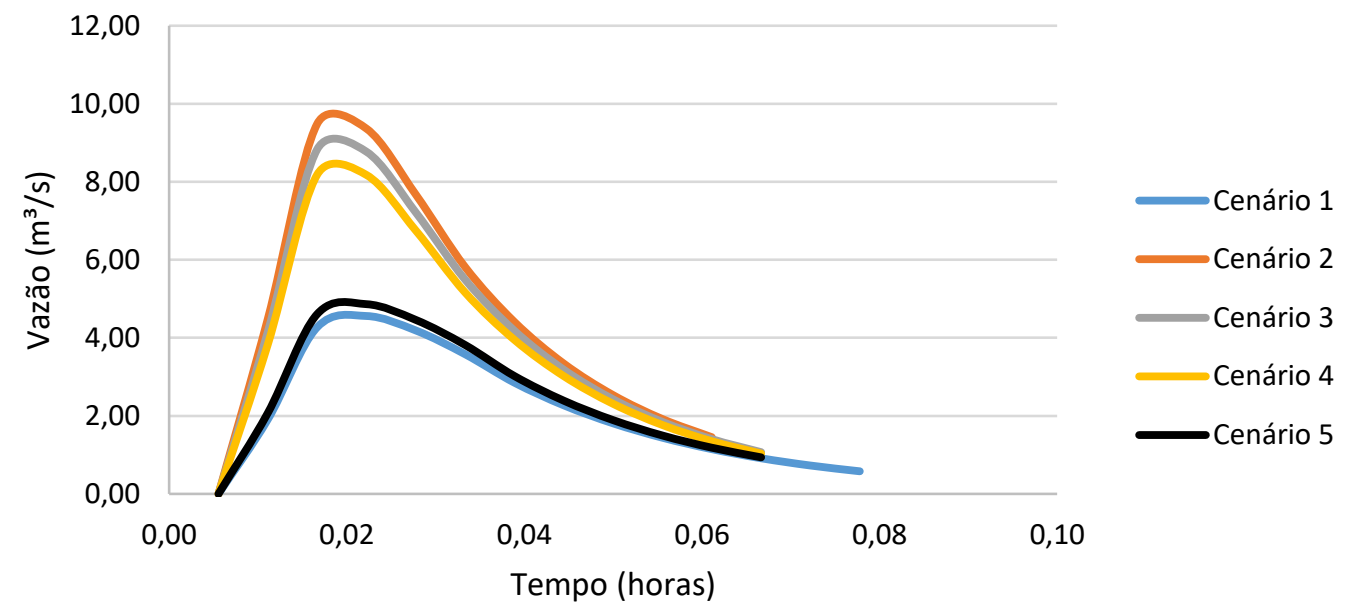

Figura C2 - Hidrograma para condição de menor eficiência para o cenário 3. Duração = tempo de concentração. Tempo de retorno 10 anos.

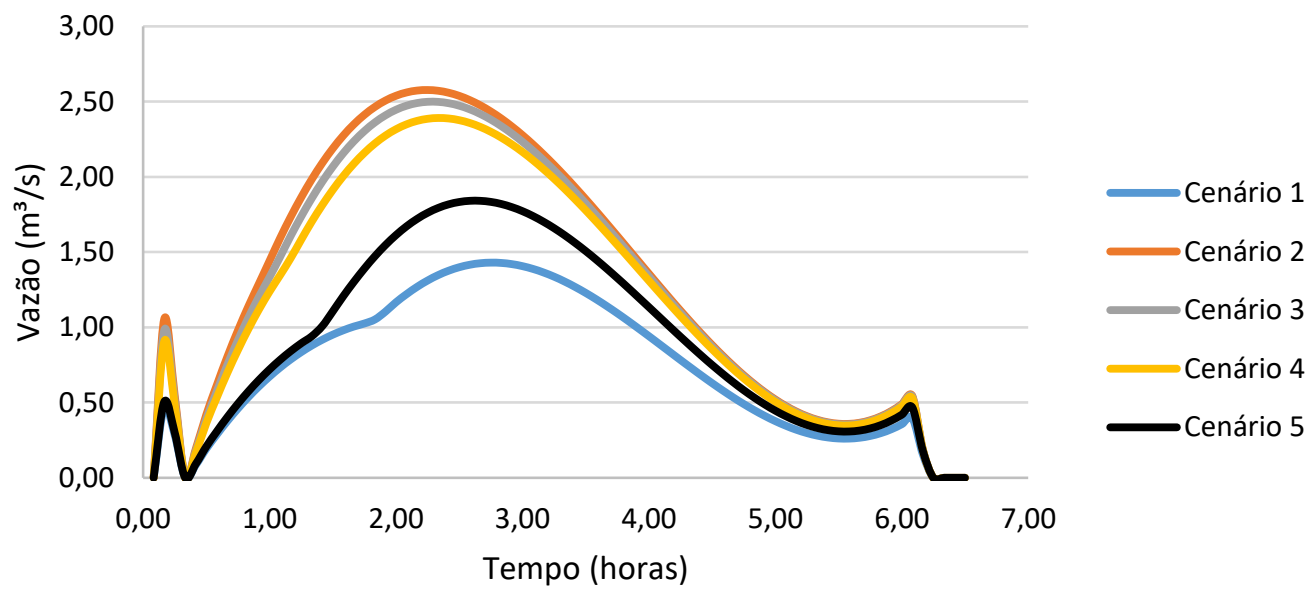

Figura C3 - Hidrograma para condição de menor eficiência para os cenários 4 e 5. Duração 6 horas. Tempo de retorno 10 anos. 